\title{
OPTIMIZED AND NUMERICAL MODELS OF ELECTROMECHANICAL DEVICES COUPLED WITH COMPUTATION OF PERFORMANCE CHARACTERISTICS
}

\author{
Vasilija Sarac * Tatjana Atanasova-Pacemska ${ }^{*}$ \\ Dragan Minovski * Goran Cogelja ${ }^{*}$ \\ Miroslava Smitková ${ }^{* *}$ - Christian Schulze ${ }^{* *}$
}

\begin{abstract}
The method of genetic algorithms is used to optimize the efficiency factor of two objects: single a phase shaded pole motor and the main inductor for an LCL filter, aimed for independent operation. By varying the construction parameters, three motors and two inductor models have been designed and optimized. The optimized motors exhibited a gradual increase of the efficiency factor achieved for the same input power. Also an increased output power has been achieved, which considerably improved the low efficiency factor for this type of the motor. The optimized filter models have an increased efficiency due to the lower losses and a decreased warm-up. All models are evaluated by the finite element method, which allows to plot the magnetic flux density distribution in the cross section and hereby the possible weak parts of the construction with a high flux density can be discovered.
\end{abstract}

K e y w or ds: single phase shaded pole motor, inductor for LCL filter, genetic algorithms, efficiency optimization

\section{INTRODUCTION}

The method of genetic algorithms (GA) belongs to the stochastic methods for optimization and in its essence it is an evolutionary searching algorithm based on the rules of natural genetics and natural mechanism of unit selection. These are implemented in the most simplified natural way, based on the survival principles of the fittest unit. The GA method serves as a tool for improving the design of electromechanical devices with respect to different optimization functions such as electromagnetic torque or efficiency factor. An important step in the optimization procedure is defining the target function for optimization [1-3]. Two objects are investigated in the described optimization procedure: the single phase shaded pole motor (SPSPM) and the main inductor for the LCL filter. Both objects exhibit "poor" efficiency factors at their rated operating point. The SPSPM motor has a robust and reliable construction as well as low production costs which contribute to the fact that this type of motor is one of the most widely spread single phase motors. Its week points are the low efficiency factor $\eta$, for this type of motor typically 0.25 to 0.4 , as well as a low power factor $\cos \varphi(0.4$ to 0.6$)$. In this paper, motor AKO-16 of MichonTech is analysed with rated motor data as follows: voltage $U_{n}=220 \mathrm{~V}$, frequency $f_{n}=50 \mathrm{~Hz}$, input current $I_{1 n}=0.125 \mathrm{~A}$, pair of poles $2 p=2$, input power $P_{1}=18 \mathrm{~W}$, rated speed $n_{n}=2520 \mathrm{rpm}$ (Fig. 1). The second object of optimization, the main inductor of the
LCL filter, has application in variable voltage variable frequency (VVVF) converters (product of company ABB) but it also has a wide range of application in adjustablespeed drives as well as in renewable energy sources. The switching frequency of the converter power is within the range from 2 to $15 \mathrm{kHz}$. This causes a huge amount of high order harmonics around the switching frequency. To reduce the current harmonics around the switching frequency a high value of input inductance should be used. Above the applications of several kilowatts it is quite expensive to realize high values of filter reactors. Therefore an LCL filter is used as an alternative. Still the presence of high order harmonics around the switching frequency is considerable, which leads to increased filter losses and a rise of filter temperature. Therefore, a mathematical model of the filter generated and implemented in GA optimization method is used to minimize the filter losses and consequently to increase the efficiency factor [4]. The electrical circuit of VVVF converter with an LCL filter is presented in Fig. 2. The rated values of the filter parameters are $U_{g}=400 \mathrm{~V}, f=50 \mathrm{~Hz}, I_{g}=60 \mathrm{~A}, L_{f g}=0.6 \mathrm{mH}$, $R_{f g}=8 \mathrm{~m} \Omega, L_{f c}=1.8 \mathrm{mH}, R_{f c}=16 \mathrm{~m} \Omega, C_{f}=60 \mu \mathrm{F}$. The value of the DC link capacitance is $C_{f}=2200 \mu \mathrm{F}$ and of the DC link voltage is $U_{D C}=670 \mathrm{~V}$. In this paper the object of optimization is the inductor placed on the converter side, also known as the main inductor $L_{f c}$. The proposed optimization methodology in the paper contributes to the improved design of the mentioned electromechanical devices.

\footnotetext{
* Faculty of Electrical Engineering, Goce Delcev University, PO Box 201, 2000 Stip, Macedonia, vasilija.sarac@ugd.edu.mk, tatjana.pacemska@ugd.edu.mk, dragan.minovski@ugd.edu.mk, goran.cogelja@ugd.edu.mk;

** Faculty of Electrical Engineering and Information Technology, Slovak University of Technology, Ilkovičova 3, Bratislava, Slovakia, miroslava.smitkova@stuba.sk, christian.cs.schulze@gmx.de
} 


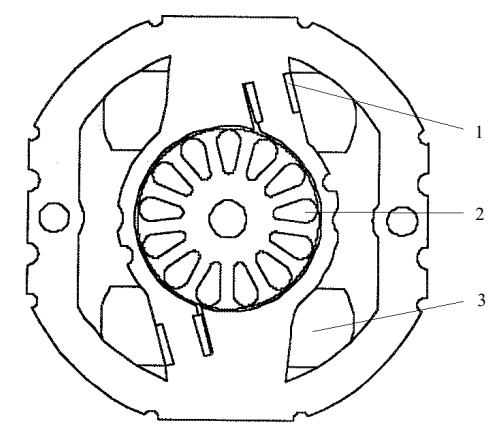

Fig. 1. SPSPM view

\section{MATHEMATICAL MODELS}

\subsection{Mathematical model of SPSPM}

Two separate stator windings exist in SPSPM which are displaced in space by an angle $\alpha \neq 90^{\circ}$ (Fig. 1). Consequently, the currents which flow through the two stator windings (main and short circuit coil) are time displaced by an angle $\beta \neq 90^{\circ}$. In this way the magnetic flux vector describes an ellipse. One approach to analysing the electromagnetic field inside the motor is the method of symmetrical components $[5,6]$.

An original mathematical model and methodology has been developed for calculation of SPSPM parameters and characteristics based on the method of symmetrical components. The accuracy of the developed methodology has been verified experimentally. The currents in the main stator winding $I_{1}$ as well as in the short circuit coil $I_{3}$ are calculated using the symmetrical components of the main stator winding $I_{1}^{+}$and $I_{1}^{-}$:

$$
\begin{aligned}
& I_{1}=-j\left(\frac{I_{1}^{-} e^{j \alpha}}{\sin \alpha}-\frac{I_{1}^{+} e^{-j \alpha}}{\sin \alpha}\right), \\
& I_{3}=j\left(\frac{I_{1}^{-}}{\sin \alpha}-\frac{I_{1}^{+}}{\sin \alpha}\right) .
\end{aligned}
$$

For impedances $Z^{+}$and $Z^{-}$the following equations are valid

$$
\begin{gathered}
Z^{+}=\frac{Z_{0} Z_{2}^{\prime+}}{Z_{2}^{\prime+}+Z_{0}}, \quad Z^{-}=\frac{Z_{0} z_{2}^{\prime-}}{Z_{2}^{\prime-}+Z_{0}}, \\
Z_{2}^{\prime+}=\frac{R_{2}^{\prime}}{s}+j X_{2}^{\prime}, \quad Z_{2}^{\prime-}=\frac{R_{2}^{\prime}}{2-s}+j X_{2}^{\prime}, \\
Z_{0}=R_{0}+j X_{0},
\end{gathered}
$$

where $s$ is motor slip, $Z_{1 a}$ and $Z_{1 b}$ are impedances of the main stator winding and short circuit coil, respectively. Zab is the mutual impedance between the main stator winding and the short circuit coil. $Z_{0}$ is the mutual impedance between the main stator winding and rotor winding, while $R_{2}^{\prime}$ and $X_{2}^{\prime}$ are rotor parameters refer to the stator winding. $\alpha$ is the space angle between the symmetry axis of the main stator winding and the short circuit coil. from

Symmetric components of the rotor current are found

$$
I_{2}^{+}=I_{1}^{+} \frac{Z_{0}}{Z_{0}+Z_{2}^{+}}, \quad I_{2}^{-}=I_{1}^{-} \frac{Z_{0}}{Z_{0}+Z_{2}^{-}}
$$

and the input power is obtained as

$$
P_{1}=U_{1}\left|I_{1}\right| \cos \phi
$$

The electromagnetic power is calculated from the symmetrical components of rotor current

$$
P_{\mathrm{em}}=\frac{2\left|I_{2}^{+}\right|^{2} R_{2}^{\prime}}{s}-\frac{2\left|I_{2}^{-}\right|^{2} R_{2}^{\prime}}{2-s} .
$$

The electromagnetic torque and mechanical power is calculated from

$$
M_{\mathrm{em}}=\frac{9.55}{n_{s}} P_{\mathrm{em}}, \quad P_{\mathrm{mech}}=P_{\mathrm{em}}(1-s) .
$$

where $n_{s}$ is the motor synchronous speed ans $s$ is the slip.

The motor output power and the efficiency factor are

$$
P_{2}=\frac{P_{\text {mech }}}{1.015}, \quad \eta=\frac{P_{2}}{P_{1}} .
$$

The motor output power is obtained from the mechanical power decreased by the value of stray losses, often difficult for measurement and IEEE-125 specifies them as $0.9-1.8 \%$ of the motor output power.

\subsection{Mathematical model of inductor}

The second object of optimization with respect to the efficiency factor is the main inductor in the LCL filter. So as to apply the method of GA to optimize the inductor, it is necessary to create a mathematical model for calculation of inductor parameters and characteristics. A methodology has been designed for calculating the inductor parameters, inductor efficiency factor and temperature rise. Different design equations are used to calculate the inductor magnetic flux density $B_{m}$, length of the air gap $l_{g}$ and winding resistance $R_{\text {coil }}$ for each phase of the 
Table 1. Ranges of variation of GA parameters and output results

\begin{tabular}{lccccc}
\hline Input varied parameter & BM & Variation range & M1 output & M2 output & M3 output \\
Current density $\Delta\left(\mathrm{A} / \mathrm{mm}^{2}\right)$ & 8 & 5 to 10 & 5.17 & 5.045 & 5 \\
Magnetic induction $B_{\delta}(\mathrm{T})$ & 0.404 & 0.4 to 0.45 & 0.40035 & 0.40035 & 0.4 \\
Angle of rotor skew $\alpha_{s k}\left({ }^{\circ} \mathrm{C}\right)$ & 17 & 15 to 20 & 15.025 & 15.008 & 15.0035 \\
Width of stator pole $b_{p}(\mathrm{~m})$ & 0.016 & 0.012 to 0.02 & $0.016=$ const & $0.016=$ const & 0.012 \\
Shading portion of stator pole $(-)$ & 0.25 & 0.2 to 0.4 & $0.25=$ const & 0.2 & 0.2 \\
\hline
\end{tabular}

Table 2. Motor operating characteristics at rated operating point

\begin{tabular}{lcccccc}
\hline Quantity & BM & M1 & M2 & M3 & Exper. & Producer \\
\hline Stator current $I_{1}(\mathrm{~A})$ & 0.126 & 0.131 & 0.128 & 0.1235 & 0.129 & $0.11 \pm 10 \%$ \\
Short circuit coil current $I_{3}(\mathrm{~A})$ & 0.0063 & 0.0065 & 0.0046 & 0.0048 & $/$ & $/$ \\
Rotor current $I_{2}(\mathrm{~A})$ & 0.0878 & 0.0923 & 0.0941 & 0.093 & $/$ & $/$ \\
Input power $P_{1}(\mathrm{~W})$ & 18.11 & 17.14 & 17.74 & 17.46 & 19.1 & $16 \pm 10 \%$ \\
Power factor $\cos \varphi(-)$ & 0.654 & 0.592 & 0.6283 & 0.643 & 0.667 & 0.6376 \\
Output power $P_{2}(\mathrm{~W})$ & 4.149 & 4.73 & 5.61 & 6 & $/$ & $/$ \\
Torque Mem $(\mathrm{mN})$ & 18.075 & 20.28 & 23.6 & 25.1 & $/$ & $/$ \\
Efficiency factor $(-)$ & 0.229 & 0.276 & 0.31 & 0.35 & $/$ & $/$ \\
\hline
\end{tabular}

inductor. Copper losses as a result of the fundamental where current harmonic in each phase are found from

$$
P_{\mathrm{Cu} 1}=\frac{1}{2} R_{\mathrm{coil}} i_{\mathrm{m} 1}^{2}
$$

where $i_{\mathrm{m} 1}$ is the maximal value of the fundamental current in each phase. Copper losses due to high order harmonics are calculated using equation [7]

$$
P_{\mathrm{Cu} \_\mathrm{fs}}=k_{\mathrm{p}} R_{\text {coil }} i_{\mathrm{m} \_\mathrm{fs}}^{2}
$$

where $k_{\mathrm{p}}$ is the proximity factor of the winding at switching frequency and $i_{\mathrm{m}_{-} \mathrm{fs}}$ is the current amplitude at switching frequency (ripple current) found from measurements. The iron core losses of the inductor due to high order harmonics $P_{\mathrm{Feh}}$ are expressed as

$$
P_{\mathrm{Feh}}=k_{\mathrm{c}} V_{\text {core }}\left(f_{1}^{\alpha} B_{\mathrm{m}}^{\beta}+f_{\mathrm{s}}^{\alpha} B_{\mathrm{m}_{-} \mathrm{fs}}^{\beta}\right)
$$

where $k_{\mathrm{c}}, \alpha, \beta$ are the constants of the lamination and their values are $k_{\mathrm{c}}=0.000557, \alpha=1.68$ and $\beta=1.68$, $V_{\text {core }}$ is the overall volume of the material, $f_{1}$ is the operating frequency and $f_{\mathrm{s}}$ is the switching frequency of the converter [8]. Flux density of the ripple current component is found from

$$
B_{\mathrm{m} \_\mathrm{ss}}=B_{\mathrm{m}} \frac{i_{\mathrm{m}_{-} \mathrm{fs}}}{i_{\mathrm{m} 1}+i_{\mathrm{m}_{-} \mathrm{fs}}} .
$$

The air gap losses generated by the fringing flux around the gap are found from

$$
P_{\text {gap }}=k_{\mathrm{g}} E_{\mathrm{x}}\left(f_{1} B_{\mathrm{m}}^{2}+f_{\mathrm{s}} B_{\mathrm{m} \_\mathrm{s}}^{2}\right) .
$$

The value of constant $k_{\mathrm{g}}$ is 0.155 and $E_{\mathrm{x}}$ is the width of the inductor leg [8]. The rise of inductor temperature is calculated as $[8]$

$$
\Delta T=450 \psi^{0,826}
$$

$$
\psi=\frac{P_{\gamma}}{A_{T}}
$$

Here, $A_{T}$ is the inductor surface area and $P_{\gamma}$ is the sum of all losses in the inductor due to the fundamental current component as well as due to higher order harmonics. The inductor efficiency factor is then given as

$$
\eta=\frac{P_{1}-\sum P_{\gamma}}{P_{1}} .
$$

Here, $P_{1}$ is the inductor input power.

Certain constraints regarding a proper operation of the LCL filter must be obeyed in mathematical calculations as well as in optimization. One of them is the resonance frequency which must be avoided at low or high order switching frequencies. To achieve a good filter performance at the switching frequency the harmonic attenuation rate $d$ must be calculated. In theory the harmonics are lower, when $d$ is low. In practice $d$ should be below $0.2[9]$.

\section{GENETIC ALGORITHMS IN OPTIMIZATION}

\subsection{Optimization of SPSPM}

Mathematical model of SPSPM suitable for GA optimization is based on the revolving field theory and the method of symmetrical components. The accuracy of the motor model known as the basic motor model (BM) is confirmed by comparing the motor characteristics with the data form experiment and from the manufacturer. The efficiency factor is adopted as a target function for optimization and three new motor models have been proposed as a result of the originally developed GA optimization motor model and designed in $\mathrm{C}++$ programming language with different numbers of input varied parameters. 


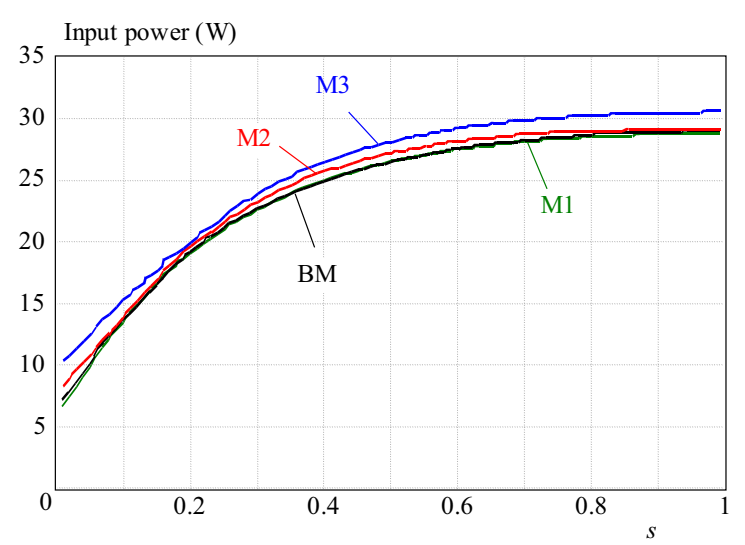

Fig. 3. Comparative characteristics of input power for all motor models

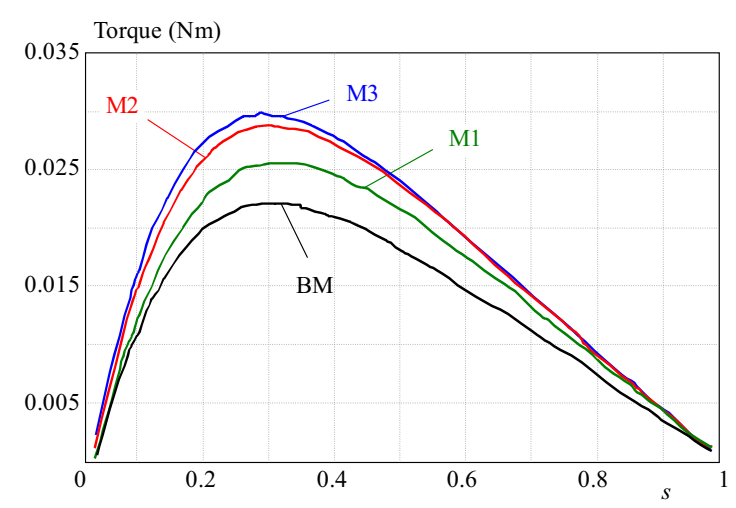

Fig. 5. Comparative characteristics of torque efficiency for all motor models

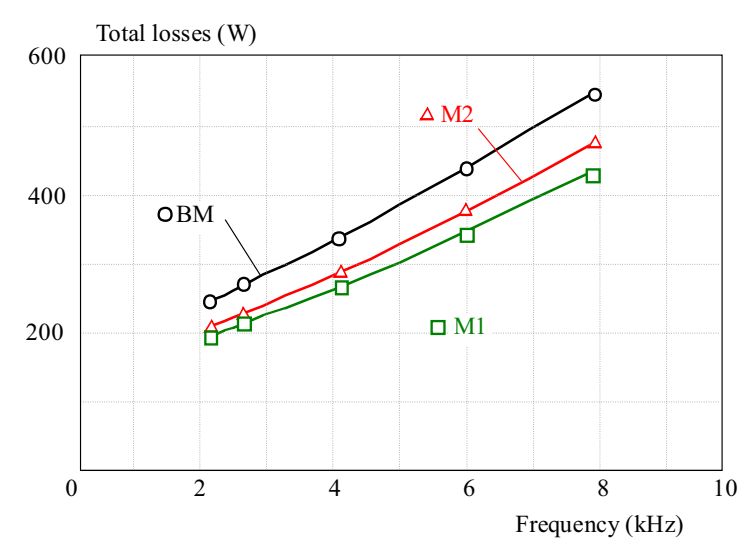

Fig. 7. Total losses at different switching frequencies

The first motor model (M1) has three input varied parameters while the second and third motor models (M2 and M3) have four and five input varied parameters. The proper choice of varied parameters and the ranges of their variation are mainly based on the designer experience and in this application certain constraints are satisfied among which motor outer dimensions remain unchanged. Table 1 shows the ranges of variation of input parameters for all motor models. Optimization is performed for the rated operating point or for motor slip $s=0.16$. During the optimization procedure, the GA based computer program is set up to create 6000 generations of varied parameters. As

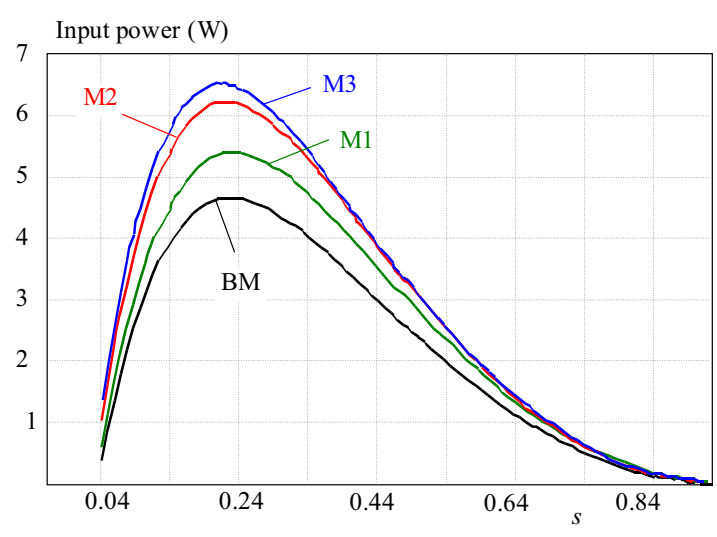

Fig. 4. Comparative characteristics of output power for all motor models

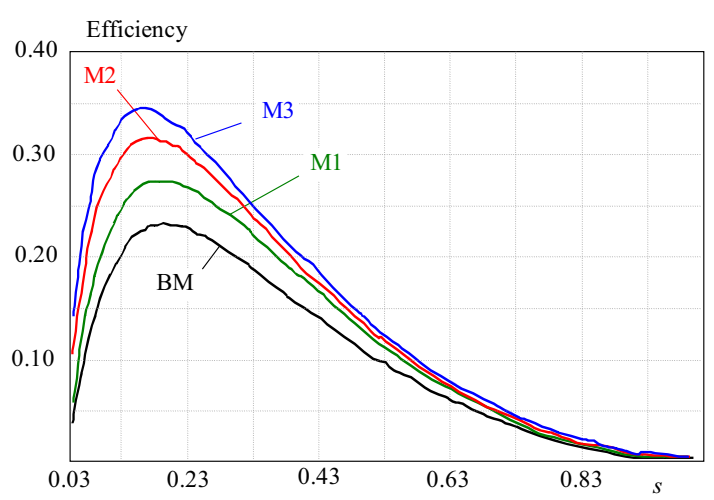

Fig. 6. Comparative characteristics of factor for all motor models

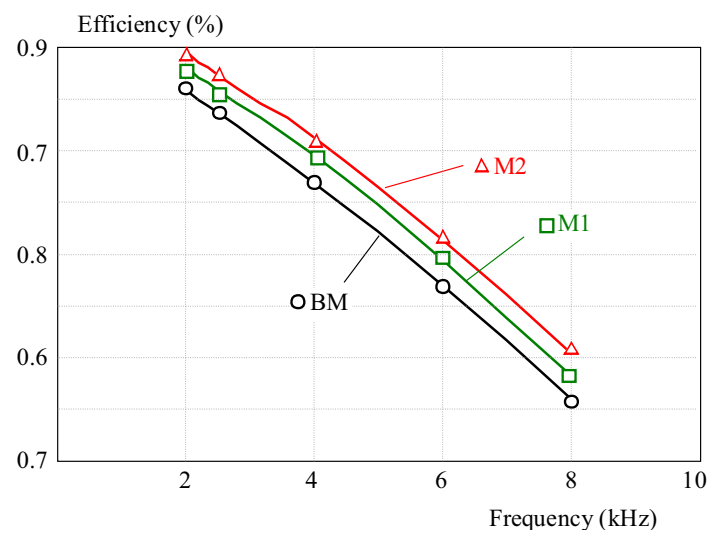

Fig. 8. Total losses at different switching frequencies

an output, the best set of varied parameters is obtained for all created models.

The output values of the varied parameters from GA optimization serve as input parameters in a code for calculating the motor characteristics. The results of motor characteristics after optimization procedure are presented in Tab. 2.

Figures 3 to 6 compare the characteristics of the input power $P_{1}$, output power $P_{2}$, electromagnetic torque $M_{\mathrm{em}}$ and efficiency factor $\eta$ for all motor models for the whole range of motor slips, $s=(0,1)$. Thus, the motor behaviour can be evaluated at all operating regimes (no 
Table 3. Optimization results for switching frequency $2.5 \mathrm{kHz}$

\begin{tabular}{lccccccccccc}
\hline & $N_{\text {turns }}(-)$ & $N_{\text {lam }}(/)$ & $P_{1}(\mathrm{~W})$ & $P_{\mathrm{Cu}}(\mathrm{W})$ & $P_{\mathrm{Fe}}(\mathrm{W})$ & $P_{\text {gap }}(\mathrm{W})$ & $P_{\gamma}(\mathrm{W})$ & $\eta$ & $\psi\left({ }^{\circ} \mathrm{C}\right)$ & $f_{\text {res }}(\mathrm{Hz})$ & $d$ \\
$\mathrm{BM}$ & 54 & 130 & 2034 & 219 & 38 & 11.07 & 268.8 & 0.868 & 97 & 969 & 0.136 \\
$\mathrm{M} 1$ & 48 & 130 & 1643 & 172 & 31.78 & 8.94 & 212.9 & 0.87 & 80.5 & 997 & 0.134 \\
$\mathrm{M} 2$ & 48 & 150 & 1895 & 183.68 & 36.66 & 8.94 & 229.3 & 0.88 & 81.8 & 977 & 0.133 \\
\hline
\end{tabular}

load, rated load and locked rotor). A gradual increase of the efficiency factor is observed starting from BM to M3. Mainly, this is a result of an increased output power, while motor power consumption, ie, the input power is slightly decreased with an unchanged value of the power factor and of the current in main stator winding. Small modifications in motor inner construction such as the angle of skew of rotor channels, width of the stator pole, shading portion of the stator pole, ie., the length of the short circuit coil as well as the magnetic flux density in the motor air gap contributed to the increase of the efficiency factor without any change of motor outer dimensions, which is important from the mounting point of view. The increase efficiency factor is a result of an increased electromagnetic power which gives also an increased motor torque, a highly desirable feature from the operation point of view.

\subsection{GA optimization of inductor}

The method of GA is implemented as an optimization tool for the main inductor of the LCL filter. The main purpose of the optimization procedure is to improve the filter design with respect to an increased efficiency factor, lower losses and decreased temperature rise. The high filter temperature is found to be a weak point of this type of filters implemented in power converters for adjustablespeed drives. Two different optimization approaches have been chosen: model 1 (M1) in which the number of turns in the inductor windings is assigned as an optimization variable, and model 2 (M2) in which the number of turns in the inductor windings and the number of steel laminations in the inductor core are selected as optimization variables. The GA always searches for the maximum value of the objective function. The objective function for this optimization search is the efficiency of the investigated inductor. A variety of original inductor models are developed for a wide range of switching frequencies from 2 to $8 \mathrm{kHz}$. In Tab. 3, the optimized parameters, the value of the objective function and some other important parameters for the inductor at the rated switching frequency of the converter $2.5 \mathrm{kHz}$ are presented. In Fig. 7 the total inductor losses are presented as a function of different switching frequencies. The inductor efficiency factor for all models is presented in Fig. 8. Both of the optimized inductor models exhibit an increased efficiency compared to the basic inductor model, decreased losses $\left(P_{\gamma}\right)$ and temperature rise $(\psi)$ as well as good harmonic attenuation rate $d$. In practice, $d$ should be below 0.2 .

\section{FINITE ELEMENT METHOD ANALYSIS}

\subsection{FEM analysis of SPSPM}

Original models of the motor and inductors suitable for FEM analysis have been developed based on the previously calculated parameters and characteristics of motors and inductors. The FEM analysis is divided into three parts: pre-processing, processing and post-processing. In pre-processing part the object geometry, as well as boundary conditions are defined. For the inductor as well as motor model Dirichlet boundary conditions are chosen $\mathbf{A}=0$, where $\mathbf{A}$ is the magnetic vector potential.

The most common use of the Dirichlet boundary conditions in magnetic problems is to define $\mathbf{A}=0$ along a boundary to keep the magnetic flux from crossing the boundary. The properties of all materials are input in the object model, including the magnetization curve $B=f(H)$ of the lamination of magnet material and the fill factor. In this way the laminations with hysteresis and eddy currents are taken into consideration for magnetic flux density calculation. In order to determine the value of the magnetic vector potential $\mathbf{A}$ it is necessary to divide the whole domain into a certain number of elements. For the inductor model the finite element mesh consisted of 2721 nodes and 5233 elements, while for the motor model of 16650 nodes and 32863 elements. For harmonic problems the permeability $\mu$ should be considered as a constant value. In the processing part the Maxwell equations are solved. For the motor and inductor analysis, a time-harmonic approach is implemented. The air gap magnetic field is always a time-varying quantity, when induction machines are analysed, and their $\mathrm{AC}$ excitation is considered. In materials with non-zero conductivity eddy currents are induced, consequently the field problem turns into a magnetodynamic, thus a non-linear time harmonic problem [10]. When the rotor is moving, the rotor quantities oscillate at slip frequency. In this case the rotor bars conductivity $\sigma$ is adjusted corresponding to the slip. Consequently the following partial equation is to be solved numerically

$$
\nabla \times\left(\frac{1}{\mu(B)} \nabla \times \mathbf{A}\right)=-\sigma \mathbf{A}+\mathbf{J}_{\mathrm{src}}-\sigma \nabla V
$$

where $\mathbf{J}_{\text {src }}$ represents the applied current source. The additional voltage gradient $\nabla V$ in $2 \mathrm{D}$ field problems is constant over the conduction body. FEM considers (20) for the case in which the field is oscillating at one fixed frequency. For this case, phasor transformation yields a steady-state equation that is solved for the amplitude and phase of $A$. In the motor model the only input is the 


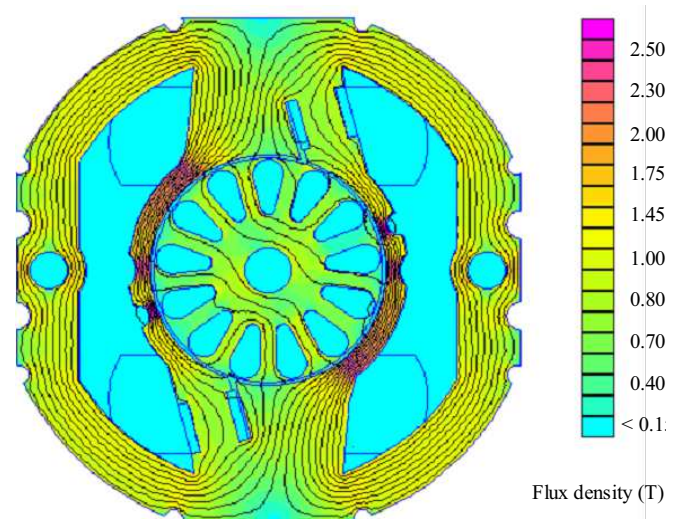

Fig. 9. Magnetic flux distribution at BM

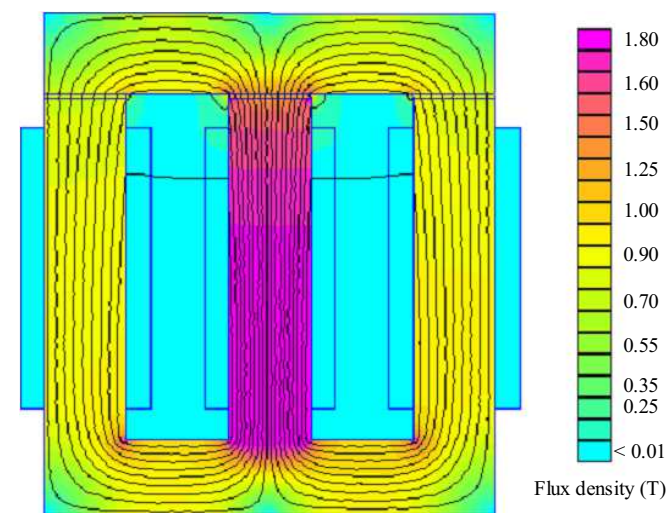

Fig. 10. Magnetic flux distribution-BM

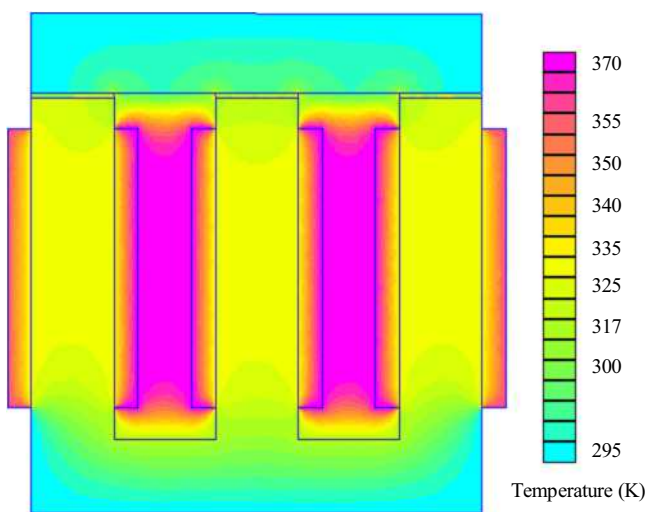

Fig. 11. Temperature distribution-BM

current in the main stator winding while the currents in the short circuit coil and rotor winding are freely induced [11-14]. Figure 9 presents the distribution of the magnetic flux density in motor cross-sections for BM.

\subsection{FEM analysis of the inductor}

FEM analysis was completed by calculation of the temperature distribution in the heat-processor module because temperature is one of the critical inductor parameters which should be lowered. Therefore two different inductor models suitable for FEM analysis were developed: the first model was implemented in the magnetic processor module and the second one in the heat-processor module of FEM software. The first model allows to calcu- late the magnetic flux density and its distribution in the inductor cross-section and the second model the temperature distribution in the inductor cross-section. The heat processor module operates in a similar way as the magnetic processor module, thus the inductor geometry, materials properties and temperature boundary conditions have to be entered for the heat distribution problem to be analysed. The heat flow problems addressed by FEM are essentially steady-state heat conduction problems. FEM solves the temperature field over a defined domain with user defined heat sources and boundary conditions. The heat flux density must obey the Gauss law, which says that the heat flux out of any closed volume is equal to the heat generation within the volume. Analogous to the electrostatic problem, this law is represented in differential form as

$$
\nabla \cdot \mathbf{F}=q
$$

where $q$ represents the heat generation per unit volume and $\mathbf{F}$ is the heat flux density. Temperature gradient and heat flux density are also related to one another via the constitutive relationship

$$
\mathbf{F}=k \mathbf{G}
$$

where $k$ is the thermal conductivity. Thermal conductivity is often a weak function of temperature.

FEM allows the variation of conductivity as an arbitrary function of the temperature and second order partial differential equation is solved

$$
-\nabla \cdot(k \nabla T)=q .
$$

These problems are represented by a temperature gradient G. The magnetic flux distribution and temperature distribution in the inductor cross-section for the basic inductor model are presented in Figs. 10 and 11. Identical results have been obtained for the two optimized inductor models.

\section{CONCLUSIONS}

The method of GA was applied to two different objects. The first one is the single phase shaded pole motor and the second one is the main inductor suitable for application in LCL filter of PWM inverter. The improvement of the efficiency factor is crucial for improvement of the overall device performance as well as for increasing the energy savings.

The first step in motor optimization is the design of an original mathematical model for calculation of the motor parameters and characteristics. Three different original optimized motor models were designed applying the GA method. The optimized motor models have a gradual increase of the number of varied input parameters from three to five, which results in a gradual increase of the motor efficiency factor from 0.229 starting for basic motor model to 0.35 in the third motor model. The achieved 
increase of the efficiency factor is a result of small alterations in motor inner construction parameters without any changes in the motor outer dimensions, which is important from the mounting point of view. The increase in the efficiency factor is obtained without increasing the motor power consumption or input current and it is mainly a result of increased output power. The increasing of the efficiency factor is accompanied by an increase of the motor electromagnetic torque from $18.075 \mathrm{mNm}$ in the basic motor model to $25.1 \mathrm{mNm}$ in third motor model.

The second object of optimization is inductor and as a first step in optimization procedure, inductor mathematical model is developed for calculation of parameters and characteristics. Again developed inductor mathematical model is used in GA program for developing two original optimized inductor models with respect to efficiency factor as optimization function. In two different optimized inductor models efficiency factor is increased from 0.868 in basic inductor model to 0.88 in second optimized inductor model, inductor losses are decreased from $269 \mathrm{~W}$ to $229 \mathrm{~W}$, temperature rise of the inductor is decreased from $97^{\circ} \mathrm{C}$ to $81.8^{\circ} \mathrm{C}$ followed by good harmonic attenuation rate well bellow recommended 0.2 .

FEM analysis has proved that the motor stator bridges are experiencing high values of magnetic flux density which are still lower in the optimized models, $2.5 \mathrm{~T}$, than in the basic motor model, $2.56 \mathrm{~T}$. This critical part of motor construction-stator bridges should be improved by using high quality magnetic materials made of soft magnetic powders in order to lower the value of magnetic flux density. Distributions of the magnetic flux density in inductor cross section and of temperature in the basic and optimized inductor models were obtained from FEM analysis. The second leg of the inductor magnetic core is experiencing higher values of magnetic flux density while the temperature rise is within expected temperature limits, lower in the optimized inductor models than in the basic model.

\section{Acknowledgment}

The research is supported by the project Functional Spaces, Topological and Statistical Aspects and their Application in Electrical Engineering financed by Goce Delcev University, Stip.

\section{REFERENCES}

[1] DONG-JOON, S.-DONG-HYEOK, CH.-JANG-SUNG, CH. - HYUN-KYO, J.: Efficiency Optimization of Interior Permanent Magnet Synchronous Motor Using Genetic Algorithms, IEEE Transaction on Magnetics 33 No. 02 (1997), 1880-1883.

[2] GKHAN-YETGIN, A.-TURAN, M. : Efficiency Optimization of Slitted-Core Induction Motor, Journal of Electrical Engineering 65 No. 01 (2014), 60-64.

[3] NUHRANOVIĆ, A.-HIVZIEFENDIĆ, J.-HADŽIMEHMEDOVIĆ, A.: Distribution Network Reconfiguration Considering Power Losses and Outages Costs Using Genetic Algorithm, Journal of Electrical Engineering 64 No. 05 (2014), 256-271.
[4] SUN, W.-CHEN, Z.-WU, X.: Intelligent Optimize Design of LCL Filter for Three-Phase Voltage-Source PWM Rectifier, IPMC 2009, 970-974.

[5] DAVIDSON, I. E. : Performance Calculation of a Shaded-Pole Single-Sided Linear Induction Motor Using Symmetrical Components and Finite Element Method, Electromotion 4 No. 04 (1997), 139-145.

[6] HAMDI, E. S. : Design of Small Electrical Machines, John Wiley \& Sons, New York, NY, USA, 1994.

[7] WEI, L.-LUKASZEWSKI, R. A.: Optimisation of the Main Inductor in a LCL Filter for Three Phase Active Rectifier, IEEE (2007), 1816-1822.

[8] MCLYMAN, W. T.: Transformer and Inductor Design Handbook, CRC Press, Idyllwild, California, USA, 2004.

[9] LISERRE, M.-BLAABJERG, F.-HANSEN, S. : Design and Control of an LCL Filter Based Three Phase Active Rectifier, IEEE Transaction on Industry Application 41 No. 05 (2005), 1281-1291

[10] MEEKER, D. : Finite Element Method Magnetics, User Manual Version 4.22007.

[11] ZHOU, D.-RAJANATHAN, C. B.-SAPELUK, A. T.-OZVEM, C. S. : Finite Element Aided Design Optimization of a Shaded Pole Induction Motor for Maximum Starting Torque, IEEE Transactions on Magnetics 36 No. 05 (2000), 3551-3554.

[12] AKBABA, M.-FAKHRO, S. Q. : Field Distribution and Iron Loss Computation in Reluctance Augmented Shaded-Pole Motors Using Finite Element Method, IEEE Transactions on Energy Conversion 7 No. 02 (1992), 302-307.

[13] GERSEM, H. DE.-HAMEYER, K.: Time-Harmonic Finite Element Simulation of Shaded-Pole Induction Machine, Proceedings on the ISEF'2001, the 10-th International Symposium on Electromagnetic Fields in Electrical Engineering (2001), 499-502.

14] GERSEM, H. DE.-HAMEYER, K.: Air-Gap Flux Splitting for the Time-Harmonic Finite-Element Simulation of Single-Phase Induction Machines, IEEE Transactions on Magnetics 38 No. 02 (2002), 1221-1224.

Received 14 August 2014

Vasilija Sarac, associate professor of the Faculty of Electrical Engineering at University Goce Delcev, Stip, Republic of Macedonia. Her main research interests include the design, simulation and optimization methods in electrical machines and power converters.

Tatjana Atanasova-Pacemska, associate professor of the Faculty of Electrical Engineering at University Goce Delcev, Stip, Republic of Macedonia. Her research field are applied mathematical methods in engineering.

Dragan Minovski, assistant professor of the Faculty of Electrical Engineering at University Goce Delcev, Stip, Republic of Macedonia. Main research interests include power transmission and distribution including power system components modelling, design and simulation.

Goran Cogelja, assistant professor of the Faculty of Electrical Engineering at University Goce Delcev, Stip, Republic of Macedonia. Main research interests include power transmission and distribution including power system components modelling, design and simulation and electricity markets.

Miroslava Smitkova, associate professor of the Faculty of Electrical Engineering and Information Technology, Slovak University of Technology in Bratislava. Her main research interest is renewable energy.

Christian Schulze, postgraduate student at the Slovak University of Technology in Bratislava. His main research interests include analysis, optimization and planning of power systems and technical environment and health protection. 